\title{
Stimulus change properties of the RT ready signal
}

CALVIN K. ADAMS AND ISAAC BEHAR

Two studies tested the generality of the Perkins-Logan hypothesis in the reaction-time experiment. Both studies used a parametric design with four ambient (intertrial) intensities of white noise ranging from 0 to $90 \mathrm{~dB}$ in all combinations with the same four intensities used as ready signals. The results were consistent with the Perkins-Logan interpretation of stimulus intensity effects as magnitude of change (increase and decrease) produced a highly significant effect in both studies. However, RTs were shorter when ready signals were decreases rather than increases in intensity (significant in one study).

Behar \& Adams (1966) have demonstrated that the ready signal in the simple reaction-time (RT) experiment has properties that are analogous to those of the $\mathrm{CS}$ in classical aversive conditioning. Thus, as ready signal intensity was increased, RT decreased significantly when a within-Ss design was used. Similarly, RTs were significantly shorter with delayed than with trace presentation of the ready signal. The interpretation given these effects was that they represent examples of Hull's Stimulus Intensity Dynamism (1949).

An alternative interpretation of stimulus intensity effects in conditioning was offered by Perkins (1953) and Logan (1954). They suggested that what may be important is not the absolute intensity of the stimulus, but the amount of contrast between the stimulus intensity and ambient or intertrial stimulation. Since most studies used a zero level intertrial stimulus, the two alternatives were confounded. A way of separating the effect due to intensity of the CS per se from that due to the contrast between its intensity and that of the background has been to employ other than zero level backgrounds. Thus, for example, Logan \& Wagner (1962) found equally efficient eyelid conditioning when the CS was either an increase or a decrease in luminance from the intertrial level.

The purpose of the present study was to test the generality of the Perkins-Logan hypothesis in the reaction-time experiment. This involved a parametric design using four ambient (intertrial) intensities of white noise ranging from 0 to $90 \mathrm{~dB}$, in all combinations with the same four intensities used as ready signals. Two experiments were conducted which differed only in one respect-whether a zero change (i.e., no ready signal) condition was included.

Method

Twelve enlisted men were used in each of Experiments I and II. Those in Experiment I were between the ages of 17 and $22 \mathrm{yr} .$, and had no experience in RT experiments. Those in Experiment II were between 22 and 34 yr. Some of them had previously participated in RT experiments, but not in Experiment I.
The intertrial and rerdy signals consisted of white noise fed into earphones. The intensities used were 0 , 30,60 , and $90 \mathrm{~dB}$ sound pressure level (SPL). The visual response signal always was an increase in luminance to $27 \mathrm{ft} .-\mathrm{c}$ from an ambient of $7 \mathrm{ft} .-\mathrm{c}$, of a diffused fluorescent lamp, masked by a circular aperture such that it subtended a visual angle of $1^{\circ}$.

The change in intensity (increase or decrease) of the white noise that constituted the ready signal was maintained throughout the fore-period (3-3.6 sec.), and overlapped with the response signal (delayed presentation). Both signals terminated simultaneously at the moment of response. The intertrial interval was $20 \mathrm{sec}$.

EXPERIMENT I.The Ss were seated in a sound treated room adjacent to that occupied by $E$ and the equipment. They were instructed to rest the index finger of the preferred hand on a metal stud centered on a spherical platform. When they heard a change in the auditory signal they were to "get ready. "As soon as the intensity of the visual signal increased they were to lift their finger straight up, off the metal contact as quickly as possible, then return it to the contact and wait for the next signal. They were cautioned not to make anticipatory responses.

Testing was conducted in five sessions, each at least one day apart. The first session, which constituted practice, contained 48 trials divided into four 12 trial blocks, each block using a different ambient level. In each of the four test sessions, the Ss received six "warm-up" trials and 48 test trials containing a constrained (runs limited to three) random ordering of the three remaining intensities as ready signals. The Ss had a different ambient level in each session. Ambient levels were counterbalanced over Ss for the four test days.

The data used for analysis were the arithmetic means of the 12 RTs for each ready signal-ambient combination remaining after the two longest and shortest RTs were eliminated for each $\mathrm{S}$.

EXPERIMENT II. The procedure was the same as that for Experiment I except that the ready signal intensity was allowed to be the same as the ambient intensity; in effect, this meant that there was no ready signal per se on one-fourth of the trials. This required two other changes: (1) no reference was made to the auditory signals in the instructions except that they would sometimes occur, and (2) the data used for analysis were the means of the 10 RTs at each intensityambient combination remaining after the longest and shortest RT had been eliminated for each S.

Results

The mean RTs for all combinations of ready signal and ambient intensity are presented in Table $\mathrm{I}$, in which the mean RTs are grouped for corresponding increases 
Table 1. Mean RT for all ambient-ready signal intensity combinations (excluding zero change). Increase and decrease refer to direction of intensity change from ambient; magnitude of change is given in left column.

\begin{tabular}{|c|c|c|c|c|c|c|c|c|c|c|}
\hline \multirow{2}{*}{ Magnitude } & \multicolumn{4}{|c|}{ EXP. I } & \multirow{2}{*}{ Mean } & \multicolumn{4}{|c|}{ EXP. II } & \multirow[t]{2}{*}{ Mean } \\
\hline & \multicolumn{2}{|c|}{ Increose } & \multicolumn{2}{|c|}{ Decrease } & & \multicolumn{2}{|c|}{ Increase } & \multicolumn{2}{|c|}{ Decrease } & \\
\hline 30 & $\begin{array}{r}0 \rightarrow 30 \\
30 \rightarrow 60 \\
60 \rightarrow 90\end{array}$ & $\begin{array}{l}244.8 \\
265.2 \\
239.1\end{array}$ & $\begin{array}{l}30 \rightarrow 0 \\
60 \rightarrow 30 \\
90 \rightarrow 60\end{array}$ & $\begin{array}{l}246.3 \\
232.1 \\
237.3\end{array}$ & 244.1 & $\begin{array}{r}0 \rightarrow 30 \\
30 \rightarrow 60 \\
60 \rightarrow 90\end{array}$ & $\begin{array}{l}296.6 \\
280.4 \\
285.0\end{array}$ & $\begin{array}{l}30 \rightarrow 0 \\
60 \rightarrow 30 \\
90 \rightarrow 60\end{array}$ & $\begin{array}{l}295.5 \\
279.5 \\
266.1\end{array}$ & 283.9 \\
\hline 60 & $\begin{array}{r}0 \rightarrow 60 \\
30 \rightarrow 90\end{array}$ & $\begin{array}{l}238.6 \\
242.6\end{array}$ & $\begin{array}{l}60 \rightarrow 0 \\
90 \rightarrow 30\end{array}$ & $\begin{array}{l}228.8 \\
235.3\end{array}$ & 236.3 & $\begin{array}{r}0 \rightarrow 60 \\
30 \rightarrow 90\end{array}$ & $\begin{array}{l}275.9 \\
272.8\end{array}$ & $\begin{array}{l}60 \rightarrow 0 \\
90 \rightarrow 30\end{array}$ & $\begin{array}{l}274.3 \\
262.2\end{array}$ & 271.3 \\
\hline 90 & $0 \rightarrow 90$ & 225.8 & $90 \rightarrow 0$ & 231.7 & 228.7 & $0 \rightarrow 90$ & 269.1 & $90 \rightarrow 0$ & 265.4 & 267.3 \\
\hline Mean & & 12.7 & 235 & & & & 0.0 & 273. & & \\
\hline
\end{tabular}

and decreases of 30,60 , and $90 \mathrm{~dB}$. For the zero change conditions of Experiment II, the mean RTs were 349.9 , $336.2,349.0$, and 326.3 with $0,30,60$, and $90 \mathrm{~dB}$ ambients, respectively. An analysis of variance of orthogonal components ${ }^{1}$ evaluated the significance of the two main effects (direction and magnitude of ready signal change) and their interaction, separately for Experiments I and II. In the first experiment, RTs averaged $7.4 \mathrm{msec}$. shorter when the ready signals were decreases in intensity than when they were increases, a difference which was significant at the .05 level $(F=4.98, \mathrm{df}=1 / 121)$. For stimulus changes of $30 \mathrm{~dB}$, the mean RT was 244.1, while for $60 \mathrm{~dB}$ it was 236.3, and for $90 \mathrm{~dB}$ it was 228.7. The differences among these means were significant at the .005 level $(F=5.90$, $\mathrm{df}=2 / 121$ ). The interaction was not significant.

In Experiment II, the $6.2 \mathrm{msec}$. mean difference between the two directions of change was not significant. With 30,60 , and $90 \mathrm{~dB}$ changes the mean RTs were $283.9,271.3$, and 267.3 ; the differences were significant at the .01 level $(F=4.88, \mathrm{df}=2 / 121)$. Again the interaction was not significant.

\section{Discussion}

With the $0 \mathrm{~dB}$ ambient level, RT decreased monotonically with increasing ready signal intensity, a result which replicates our previous finding (Behar \& Adams, 1966). The present results extend this finding in showing that corresponding results obtain when the ready signals consist either of increments or decrements from the intertrial intensity, providing strong support for the generality of the Perkins-Logan hypothesis in the RT task. Thus, we may conclude that the effectiveness of the $\mathrm{RT}$ ready signal in producing short reaction times is directly related to the magnitude of intensity change in either direction from the background intensity.

The significant direction (increase vs. decrease) effect found in Experiment I suggests that this conclusion may not be unequivocally correct. The significantly shorter RTs for decreases in ready signal intensity suggests that the intertrial intensity also influence the $\mathrm{RT}$. The mean intertrial intensity for the "increase" conditions was $20 \mathrm{~dB}$ while for the "decrease" conditions it was $70 \mathrm{~dB}$. Furthermore, with the $90 \mathrm{~dB}$ ambient, RTs at all ready signal levels were about the same, and approximately equal to those obtained with the $90 \mathrm{~dB}$ signal under the $0 \mathrm{~dB}$ ambient condition.
This implies that a relatively small decrease, from a high ambient, may be as effective as a large increase from zero ambient. In an additional study, using the general conditions of Experiment I with eight Ss the effectiveness was tested of ready signals consisting of decreases of only 10,20 , or $30 \mathrm{~dB}$ from the ambient of $90 \mathrm{~dB}$. The mean RTs were $222.9,217.4$, and 222.1 msec. for decreases of 10,20 , and $30 \mathrm{~dB}$, respectively. The differences were not significant. Here also then, RTs were very short and were not proportional to magnitude of stimulus change. Taken together, the results suggest that high ambients exert some form of facilitatory effect.

An interesting aspect of the results of Experiment II is that they illustrate the pronounced increase in RT when the ready signal is omitted, of the order of 50 msec. A more subtle effect of ready signal variation is the large difference in RT between Experiments I and II for the trials in which the ready signals were comparable. We attribute the longer RTs of Experiment II to the presence of no-ready-signal trials, which increased the Ss' uncertainty regarding the ready signal. Further evidence for the role of ready signal uncertainty was provided in our previous paper (Behar \& Adams, 1966).

The mechanism by which variation of the ready signal influences the reaction time may be one of differential arousal, or, as we have previously suggested, the RT ready signal serves as a true CS in conditioning, or eliciting already conditioned, preparatory responses, the presence or absence of which then determines the speed of response. Hence, the more effective the ready signal is as a CS, the shorter will be RT.

\section{References}

Behar, I., \& Adams, C. K. Some properties of the reaction-time ready signal. Amer. J. Psychol., 1966, 79, 419-426.

Hull, C. L. Stimulus intensity dynamism (V) and stimulus generalization. Psychol. Rev., 1949, 56, 67-76.

Logan, F. A. A note on stimuius intensity dynamism (V). Psychol. Rev., 1954, 61, 77-80.

Logan, F. A., \& Wagner, A. R. Direction of change in CS in eyelid conditioning. J. exp. Psychol., 1962, 64, 325-326.

Perkins, C. C., Jr. The relation between conditioned stimulus intensity and response strength. J. exp. Psychol., 1953, 46, $225-231$.

\section{Note}

1. We thank Dr. Earl Alluisi for suggesting this procedure. 